\title{
NOTAS SOBRE AS POSSÍVEIS CONTRIBUIÇÕES DE THEODOR W. ADORNO PARA ESTUDOS SOBRE O LAZER ${ }^{1}$
}

Recebido em: 10/04/2009

Aceito em: 20/08/2009

\author{
Renata Morais do Nascimento ${ }^{2}$ \\ UNIMEP - GPL - CNPq \\ Piracicaba - SP - Brasil; \\ Nelson Carvalho Marcellino ${ }^{3}$ \\ UNIMEP - GPL - ORICOLÉ, CNPq - RedeCEDES \\ Piracicaba - SP - Brasil.
}

RESUMO: O presente artigo é resultado de uma pesquisa de revisão bibliográfica que tem como objetivo destacar as principais considerações do pensador alemão Theodor W. Adorno, e suas possíveis contribuições para o embasamento teórico em trabalhos que abordem questões relacionadas aos estudos do lazer. Privilegiamos a abordagem de Tempo Livre por considerarmos que com esse texto podemos avançar melhor aos objetivos traçados, por tratar-se de um trabalho que tem recebido menos destaque, segundo levantamento bibliográfico que efetuamos acerca de estudos sobre Adorno, bem como por não ter como principal foco - no que diz respeito à abordagem de questões relacionadas ao lazer, o estudo da Indústria Cultural.

PALAVRAS-CHAVE: Atividades de Lazer. Filosofia. Indústria Cultural.

\section{NOTES ON THE POSSIBLE CONTRIBUTIONS OF THEODOR W. ADORNO TO STUDIES ON LEISURE}

ABSTRACT: The present article is the product of a bibliographical research that aims at highlighting German thinker Theodor W. Adorno's primary considerations and his possible contributions to the development of a theoretical basis for studies on leisure. We privileged approaching his text on "Free Time" as we consider that by using it we

\footnotetext{
${ }^{1}$ Trabalho originado do projeto de Iniciação Científica intitulado "Construção de uma teoria do lazer a Partir dos autores clássicos: as contribuições de ADORNO, HORKHEIMER, MARCUSE E BENJAMIN", financiado pelo CNPq, apresentado em outubro de 2008 , no $6^{\circ}$ Congresso de Iniciação Científica, na $6^{\circ}$ Mostra Acadêmica da UNIMEP.

${ }^{2}$ Aluna concluinte no curso de Licenciatura em História da UNIMEP, bolsista de iniciação científica do CNPq, membro do GPL - Grupo de Pesquisa em Lazer.

${ }^{3}$ Docente do mestrado e graduação em Educação Física, da UNIMEP, Coordenador do Núcleo da Rede Cedes, Líder do GPL-Grupo de Pesquisa em Lazer-UNIMEP, membro do ORICOLÉ, Laboratório de pesquisa sobre formação e atuação profissional-UFMG, e pesquisador do CNPq.
} 
can better advance towards our established purposes, since it is a work that received less attention, according to our bibliographical research on Adorno's studies. Besides regarding issues related to leisure - it does not focus primarily on the study of the Cultural Industry.

KEYWORDS: Leisure Activities. Philosophy. Cultural Industry.

Pouca coisa distingue tão a fundo o modo de vida que convém ao intelectual daquele do burguês do que a recusa do intelectual a reconhecer a alternativa de trabalho ou diversão. $O$ trabalho não obrigado a impor ao seu sujeito, em nome da realidade, tudo que de mau ele depois deverá impor a outros é prazer mesmo no esforço mais desesperado. A liberdade visada por ele é a mesma que a sociedade burguesa reserva exclusivamente ao descanso e, ao assim regulamentar, no mesmo passo lhe retira. Inversamente, para aquele que sabe da liberdade, todo divertimento admitido por tal sociedade é intolerável, e fora do seu trabalho, que decerto inclui tudo aquilo que os burgueses relegam ao feriado como "cultura", não lhe apetece qualquer prazer substitutivo. Trabalho é coisa séria, brincadeira tem hora - isso conta entre as regras básicas da autodisciplina repressiva. [...] Apenas a ardilosa fusão de prazer e trabalho ainda mantém aberta a experiência autentica sob a pressão da sociedade. Ela é tolerada cada vez menos. [...] Nenhum prazer pode aderir ao trabalho, que do contrário perderia sua modesta funcional na totalidade dos fins, nenhuma centelha da consciência pode cair no tempo de lazer, pois de outro modo ela poderia saltar para o mundo do trabalho e pô-lo em chamas. Enquanto o trabalho e o divertimento cada vez se assemelham mais na estrutura, com tanto mais rigor eles são apartadas por linhas de demarcação invisíveis. De ambos o prazer e o espírito foram igualmente expulsos. Em um como no outro rege a seriedade bovina e a pseudo-atividade.

T.W. ADORNO, Mínima Moralia.

\section{Introdução}

O presente trabalho visa destacar algumas contribuições do pensamento do filósofo alemão Theodor W. Adorno para os estudos sobre lazer - entendido aqui como conceito que agrega atividades praticadas no chamado tempo livre.

Dessa forma, a partir da leitura de várias obras do autor, selecionamos alguns textos que consideramos essenciais para a abordagem que pretendemos realizar: $A$ Indústria Cultural: O esclarecimento como mistificação das massas (HORKHEIMER; ADORNO, 1985); Crítica cultural e sociedade (ADORNO, 1998); e Tempo livre (ADORNO, 1995). Privilegiamos a abordagem de Tempo Livre por considerarmos que 
com esse texto podemos avançar melhor aos objetivos traçados, por tratar-se de um trabalho que tem recebido menos destaque, segundo levantamento bibliográfico que efetuamos acerca de estudos sobre Adorno, bem como por não ter como principal foco no que diz respeito à abordagem de questões relacionadas ao lazer -, o estudo da Indústria Cultural, mas sim uma análise que aborda também outros aspectos que permeiam a questão do "tempo livre".

\section{Problemáticas relacionadas ao conceito de Tempo Livre}

Tempo livre é um texto que surgiu de uma conferência transmitida pela "Rádio Alemanha” em 1969 - ano da morte de Adorno -, que tem por objetivo tratar da questão do "tempo livre". O que as pessoas fazem durante o tempo disponível do trabalho, e quais as chances oferecidas para seu desenvolvimento.

Adorno faz a diferenciação entre os conceitos de ócio e tempo livre. Segundo afirma, o ócio, expressão anterior, referia-se ao privilégio de uma vida folgada. Já a expressão tempo livre, de origem recente, apontaria para a diferença desse em relação ao tempo não livre - o de trabalho.

Ao falar sobre o chamado tempo livre, Adorno está tratando do que o historiador inglês E. P. Thompson chamou de disciplina do tempo. Em Tempo, disciplina de trabalho e o capitalismo industrial (THOMPSON, 1998), Thompson elaborou um texto resultado de pesquisa na qual analisou novos costumes e valores formados a partir da marcação do tempo por meio do uso do relógio - abordando principalmente séculos XVII, XVIII e XIX. Essa nova forma de marcar o tempo teria formado novos hábitos e nova disciplina de trabalho, impondo o surgimento de uma nova disciplina do tempo de trabalho que garantiria o controle do ócio, questões que seriam importantes na garantia do progresso do capitalismo industrial. Thompson ressalta que a imposição de uma nova 
disciplina, que contraria antigos hábitos populares de trabalho, resultou em contestação e luta pelo tempo - redução de horas de trabalho. Quando Adorno fala de tempo de trabalho e tempo livre do trabalho, está tratando dessa nova disciplina do tempo que passa a ser dividido em duas partes, a do trabalho e a supostamente livre.

Para Adorno, a divisão, e oposição, do tempo em duas metades imprime traços essenciais no tempo livre, fazendo com que esse seja determinado e acorrentado ao seu oposto, o tempo de trabalho. Além disso, o tempo livre dependeria da situação geral da sociedade que, segundo Adorno, mantém as pessoas sob um fascínio que as fazem não ter liberdade em tempo algum. Em suas palavras, "nem em seu trabalho, nem em sua consciência dispõem de si mesmas com real liberdade” (ADORNO, 1995, p.70).

A distinção entre trabalho e tempo livre foi incutida como norma à consciência e inconsciência das pessoas. Como, segundo a moral do trabalho vigente, o tempo em que se está livre do trabalho tem por função restaurar a força de trabalho, o tempo livre do trabalho precisamente porque é um mero apêndice do trabalho - vem a ser separado desse com zelo puritano [...]. Por um lado deve-se estar concentrado no trabalho, não se distrair, não cometer disparates; [...] por outro lado, deve o tempo livre, provavelmente para que depois se possa trabalhar melhor, não lembrar em nada o trabalho. Esta é a razão da imbecilidade de muitas ocupações do tempo livre. Por baixo do pano, porém, são introduzidas, de contrabando, formas de comportamento próprias do trabalho, o qual não dá folga às pessoas (ADORNO, 1995, p. 73).

Adorno critica a divisão da vida em duas metades como enaltecedora da coisificação que subjuga o tempo livre ao tempo de trabalho. Por isso a afirmação de que não se pode traçar uma divisão simples entre as pessoas e seus chamados papéis sociais.

Estes penetram profundamente nas próprias características das pessoas, em sua constituição íntima. Numa época de integração social sem precedentes, fica difícil estabelecer de forma geral, o que resta nas pessoas, além do determinado pelas funções. Isto pesa muito sobre a questão do tempo livre. Não significa menos do que, mesmo onde o encantamento se atenua e as pessoas estão ao menos subjetivamente convictas de que agem por vontade própria, essa 
vontade é modelada por aquilo de que desejam estar livres fora do horário de trabalho (ADORNO, 1995, p. 70-71).

Assim, ao analisar o tempo livre, determinado pela situação de sua sociedade contemporânea, Adorno sugere que a questão então adequada sobre o tempo livre seria a respeito do "que ocorre com ele com o aumento da produtividade no trabalho, mas persistindo as condições de não-liberdade, isto é, sob relações de produção em que as pessoas nascem inseridas e que, hoje, como antes, lhes prescrevem as regras de sua existência?” (ADORNO, 1995, p.71).

Segundo afirma, responder essa questão leva a imperar o que seria uma suspeita de que "o tempo livre tende em direção contrária à de seu próprio conceito, tornandose paródia deste. Nele se prolonga a não-liberdade” (ADORNO, 1995, p. 71). Isso porque, para o pensador frankfurtiano, no tempo livre prolonga-se a não-liberdade do tempo de trabalho.

Adorno sugere também que, se tomar-se como verdadeiro o pensamento de Marx "de que na sociedade burguesa a força de trabalho tornou-se mercadoria e, por isso, o trabalho foi coisificado" (ADORNO, 1995, p. 72), há de se aceitar que, paradoxalmente, aquilo que se entende como contrário ao trabalho coisificado, o tempo livre $^{4}$, é "coisificado da mesma maneira que a rígida delimitação entre trabalho e tempo livre", pois, "neste prolongam-se as formas de vida social organizada segundo o regime do lucro" (ADORNO, 1995, pp. 72 - 73).

Exemplos do tempo livre organizado em função do lucro são, segundo Adorno, o turismo e o camping, atividades do tempo livre ligadas às necessidades das pessoas e institucionalizadas como forma de obter lucro em um sistema funcional. A indústria do camping, para Adorno, é a institucionalização da necessidade de escape, a funcionalização da necessidade de liberdade, que passa a ser reproduzida pelo comércio

\footnotetext{
${ }^{4}$ Aqui Adorno está tratando do chamado "hobby", atividades para passar o tempo.
} 
que impõe a compra de algo que satisfaça vontades. Dessa forma, o tempo livre seria imposto sem dificuldades, numa sociedade que impinge o que deve ser o tempo livre, fazendo com que "as pessoas não percebam o quanto não são livres lá onde mais livres se sentem, porque a regra de tal ausência de liberdade foi abstraída delas" (ADORNO, 1995, p. 74).

Um aspecto entendido por Adorno como decisivo do tempo livre em sua contemporaneidade, é o tédio, que define como o sempre-igual do qual o tempo livre dificilmente consegue escapar.

O tédio existe em função da vida sob a coação do trabalho e sob a rigorosa divisão do trabalho. Não teria que existir. Sempre que a conduta no tempo livre é verdadeiramente autônoma, determinada pelas próprias pessoas enquanto seres livres, é difícil que se instale o tédio; tampouco ali onde elas perseguem seu anseio de felicidade, ou onde sua atividade no tempo livre é racional em si mesma, como algo em si pleno de sentido. O próprio bobear não precisa ser obtuso, podendo ser beatificamente desfrutado como dispensa dos autocontroles. Se as pessoas pudessem decidir sobre si mesmas e sobre suas vidas, se não estivessem encerradas no sempre-igual, então não se entediariam (ADORNO, 1995, p. 76).

Segundo Adorno, ocorre com o tédio o mesmo que se observa na apatia política.

Devido ao sentimento das massas de que com a participação política lhes conferida pela sociedade, entendendo pouco podem mudar em sua existência, recuam diante da atividade política. O mesmo ocorreria com o tédio que, para Adorno, é o desespero objetivo, e está intimamente ligado ao sentimento de impotência. Porém, também estaria relacionado a deformações produzidas pela sociedade nas pessoas, deformações das quais Adorno afirma que a mais importante é a detração da fantasia e seu atrofiamento.

Quem quiser adaptar-se, deve renunciar cada vez mais à fantasia. Em geral, mutilada por alguma experiência de primeira infância, nem consegue desenvolvê-la. A falta de fantasia, implantada e insistentemente recomendada pela sociedade, deixa as pessoas desamparadas em seu tempo livre. A pergunta descarada sobre o que o povo fará com todo o tempo livre de que hoje dispõe - como se este fosse uma esmola e não um direito humano - baseia-se nisso. Que 
efetivamente as pessoas só consigam fazer tão pouco de seu tempo livre se deve a que, de antemão, já lhes foi amputado o que poderia tornar prazeroso o tempo livre. Tanto ele lhes foi recusado e difamado que já nem o querem mais (ADORNO, 1995, pp. 76-77).

Assim, uma vez que se destruiu nas pessoas a sua produtividade e capacidade criativa, seria insensato esperar que essas façam algo de produtivo e criativo em seu tempo livre. Segundo Adorno, o que produzem são, no máximo, imitações e produções supérfluas. As atividades supérfluas, para Adorno, são integradas pela sociedade a partir de certas formas de serviços, especialmente os domésticos. Assim surgiria o "faça você mesmo", a que Adorno faz duras críticas.

O "do it yourself", um tipo de comportamento recomendado atualmente para o tempo livre, inscreve-se, não obstante, em um contexto mais amplo. Eu já o designei, há mais de trinta anos atrás, como pseudo-atividade. (...) Pseudo-atividade é espontaneidade malorientada. Mal-orientada, mas não por acaso, e sim porque as pessoas pressentem surdamente quão difícil seria para elas mudar o que pesa sobre seus ombros. Prefere deixar-se desviar para atividades aparentes, ilusórias, para satisfações compensatórias institucionalizadas, a tomar consciência de quão obstruída está hoje tal possibilidade. Pseudo-atividades são ficções e paródias daquela produtividade que a sociedade, por um lado, reclama incessantemente e, por outro lado, refreia e não quer muito nos indivíduos. Tempo livre produtivo só seria possível para pessoas emancipadas, não para aquelas que, sob a heteronomia, tornaram-se heterônomas também para si próprias (ADORNO, 1995, pp. 78-79).

Utilizando-se de sua própria experiência como exemplo, Adorno buscou esclarecer a problemática exposta a partir da forma como se ocupava nas suas horas de trabalho e nas horas de não-trabalho, as quais não teriam grandes diferenças entre si. Isso ocorreria devido a não existência de estrita oposição entre as atividades de sua profissão e as atividades de seu tempo livre - um benefício por ter tido a oportunidade de escolher e organizar seu trabalho de acordo com as suas próprias intenções. Para Adorno, o tempo livre como benefício efetivo, e não privilégio, de todos, caso um dia viesse a ocorrer, seria equivalente ao que observou em si mesmo. 
Adorno finaliza o trabalho com considerações acerca da indústria cultural, mas antes se faz necessário estudar outros trabalhos em que o autor aborda o assunto.

\section{Considerações acerca da chamada Indústria Cultural e significados de sua "ação" no "tempo livre"}

O conceito de indústria cultural foi cunhado pela primeira vez, por Adorno e Horkheimer, em Dialética do Esclarecimento - trabalho publicado em fins da década de 1940 -, mais especificamente no capítulo A Indústria Cultural: O esclarecimento como mistificação das massas.

Para analisar esse texto, é preciso ter em vista um ponto fundamental de Dialética do Esclarecimento. Em busca de uma resposta ao porque de a humanidade manifestar cada vez mais sintomas de barbárie, Horkheimer e Adorno elaboraram uma crítica à racionalização, que teria libertado o homem dos poderes míticos da natureza por meio da filosofia e da ciência, culminando numa sociedade dita esclarecida. Os autores chegam à conclusão de que essa sociedade não é de fato esclarecida. A ciência teria gerado cada vez mais tecnologia, que, por sua vez, seria responsável por uma dominação inconsciente do homem.

Para Adorno e Horkheimer (1985), a sociedade é ainda mítica, porém o mito está recalcado, excluído inconscientemente. O que querem dizer é que a tecnologia cria o mito do progresso, no qual o homem acredita que domina a natureza, porém, esse progresso acarreta em problemas que não consegue resolver. Seria um comportamento auto-destrutivo. A sociedade do progresso tecnológico domina o homem, inconscientemente, e essa dominação gera barbárie.

O termo Indústria Cultural denuncia na cultura o que antes era arte e agora técnica, produzida como mercadoria. Refere-se também à difusão de produtos culturais a nível comercial e autoritário, como forma de adaptar as massas às mercadorias. 
A ideologia da Indústria Cultural seria dominação por meio da disseminação de produtos padronizados, destinados ao consumo das massas, como se tivessem que satisfazer necessidades iguais. Essa padronização, aceita sem resistência, culminaria na falta de autonomia dos indivíduos, e na sua dominação inconsciente. A Indústria Cultural seria a destruição da capacidade crítica da obra de arte, dominando assim os indivíduos. É bom atentar para a explicação de Alexandre Vaz:

Quando Horkheimer e Adorno empregaram pela primeira vez a expressão indústria cultural, nos anos quarenta do século passado, em um dos livros mais importantes do pensamento contemporâneo - o conjunto de fragmentos filosóficos que compõe a Dialética do esclarecimento -, pretendiam esclarecer uma possível confusão. Disse Adorno, anos mais tarde, que não utilizaram o termo cultura de massas, já então bastante empregado, porque não queriam que o objeto a que se dedicavam fosse confundido com a cultura popular. Não se referiam, portanto, a uma cultura que vem das massas, mas, essencialmente, a um conjunto de artefatos produzido para as massas consumidoras. Tinham em mente o cinema, o rádio, as revistas ilustradas, seções de jornais diários e, algum tempo depois, a televisão. $\mathrm{O}$ conceito indústria cultural procura compreender as condições de produção e reprodução social em uma de suas faces mais importantes, relacionada à mercadorização da cultura, sua banalização e reificação. $\mathrm{O}$ que nossos autores supunham como inteiramente novo - já que parece desde muito ter havido algum tipo de negócio com os artefatos culturais - é que a cultura passa a ser produzida na esfera da circulação e do consumo para o entretenimento e ocupação do "tempo livre" (VAZ, 2006, p. 15).

Sobre a ação desses produtos na massa consumidora, Adorno e Horkheimer

afirmam que:

A velha experiência do espectador de cinema, que percebe a rua como um prolongamento do filme que acabou de ver, porque este pretende ele próprio reproduzir rigorosamente o mundo da percepção quotidiana, tornou-se a norma da produção. Quanto maior a perfeição com que suas técnicas duplicam os objetos empíricos, mais fácil se torna hoje obter a ilusão de que o mundo exterior é o prolongamento sem ruptura do mundo que se descobre no filme. Desde a súbita introdução do filme sonoro, a reprodução mecânica pôs-se ao inteiro serviço desse projeto. A vida não deve mais, tendencialmente, deixarse distinguir do filme sonoro. Ultrapassando de longe o teatro de ilusões, o filme não deixa mais à fantasia e ao pensamento dos espectadores nenhuma dimensão na qual estes possam, sem perder o fio, passear e divagar no quadro da obra fílmica, permanecendo, no 
entanto, livres do controle de seus dados exatos, e é assim precisamente que o filme adestra o espectador entregue a ele para se identificar imediatamente com a realidade. Atualmente, a atrofia da imaginação e da espontaneidade do consumidor cultural não precisa ser reduzida a mecanismos psicológicos. Os próprios produtos - e entre eles em primeiro lugar o mais característico, o filme sonoro paralisam essas capacidades em virtude de sua própria constituição objetiva. São feitos de tal forma que sua apreensão adequada exige, é verdade, presteza, dom de observação, conhecimentos específicos, mas também de tal sorte que proíbem a atividade intelectual do espectador, se ele não quiser perder os fatos que desfilam velozmente diante de seus olhos. O esforço, contudo, está tão profundamente inculcado que não precisa ser atualizado em cada caso para recalcar a imaginação. Quem está tão absorvido pelo universo do filme - pelos gestos, imagens e palavras -, que não precisa lhe acrescentar aquilo que fez dele um universo, não precisa necessariamente estar inteiramente dominado no momento da exibição pelos efeitos particulares dessa maquinaria. Os outros filmes e produtos culturais que deve obrigatoriamente conhecer tornaram-no tão familiarizado com os desempenhos exigidos da atenção, que estes têm lugar automaticamente. A violência da sociedade industrial instalou-se nos homens de uma vez por todas. Os produtos da indústria cultural podem ter a certeza de que até mesmo os distraídos vão consumi-los alertamente. Cada qual é um modelo da gigantesca maquinaria econômica que, desde o início, não dá folga a ninguém, tanto no trabalho quanto no descanso, que tanto se assemelha ao trabalho. É possível depreender de qualquer filme sonoro, de qualquer emissão de rádio, o impacto que não se poderia atribuir a nenhum deles isoladamente, mas só a todos em conjunto na sociedade. Inevitavelmente, cada manifestação da indústria cultural reproduz as pessoas tais como as modelou a indústria em seu todo (HORKEIMER; ADORNO, 1985, p. 118-119).

O longo trecho citado explicita a tese de que os produtos da Indústria Cultural criam uma diversão alienante. A ilusão de que o mundo é uma extensão daquilo que se vê no filme faz com que a conformidade mostrada nesse habitue os indivíduos a um padrão de comportamento. Os produtos da indústria cultural, segundo Adorno e Horkheimer, reproduzem as pessoas da mesma forma como as modela em momentos de trabalho e de descanso. Isso resultaria no controle dos instintos emancipatórios, críticos e revolucionários das massas, promovendo assim a manutenção do sistema.

Segundo os autores, os indivíduos - na necessidade de momentos de lazer e fuga do trabalho, se submetem aos produtos da indústria cultural que, por sua vez, prometendo essa fuga do trabalho, na verdade oferecem atrações que reproduzem o 
cotidiano do trabalho como se fosse novidade. Falam de um lazer padronizado que converte as atividades de lazer em prolongamento do trabalho.

A diversão é um prolongamento do trabalho sob o capitalismo tardio. Ela é procurada por quem quer escapar ao processo de trabalho mecanizado, para se pôr de novo em condições de enfrentálo. Mas, ao mesmo tempo, a mecanização atingiu um tal poderio sobre a pessoa em seu lazer e sobre a sua felicidade, ela determina tão profundamente a fabricação das mercadorias destinadas à diversão, que esta pessoa não pode mais perceber oura coisa senão as cópias que reproduzem o próprio processo de trabalho. O pretenso conteúdo não passa de uma fachada desbotada; o que fica gravado é a sequiência automatizada de operações padronizadas. Ao processo de trabalho na fábrica e no escritório só se pode escapar adaptando-se a ele durante o ócio. Eis aí a doença incurável de toda diversão. O prazer acaba por se congelar no aborrecimento, porquanto, para continuar a ser um prazer, não deve mais exigir esforço e, por isso, tem de se mover rigorosamente nos trilhos gastos das associações habituais. $O$ espectador não deve ter necessidade de nenhum pensamento próprio, o produto prescreve toda sua reação... (HORKEIMER; ADORNO, 1985, p. 128).

Assim, Adorno e Horkheimer diagnosticam os produtos da indústria cultural, nos momentos de lazer, como repressores das liberdades individuais, que padronizam e conformam as massas, condicionando-as ao mundo do trabalho.

Tese semelhante é encontrada em Crítica Cultural e Sociedade, ensaio de Theodor W. Adorno.

Em linhas gerais, a partir da leitura do texto pode-se apreender que, segundo Adorno, a sociedade é opressora, altamente competitiva - tendo em vista o mercado, e repressora das liberdades individuais. Os indivíduos são indivíduos massificados mesmo que inconscientemente - a cultura é uma cultura de massa, mercantilizada como todas as esferas da vida humana, padronizada a toda a sociedade. Isso não significa a total ausência diferenças e exceções, mas sim a existência de um padrão estabelecido, ao qual dificilmente se oferece resistência. Pelo contrário, para Adorno, haveria tentativa total de adesão - cada vez maior - a esse padrão, e mesmo os poucos resistentes 
não poderiam esquivar-se totalmente dessas características da sociedade de que fazem parte.

Em um mundo onde a educação é um privilégio e o aprisionamento da consciência impede de toda maneira o acesso das massas à experiência autêntica das formações espirituais, já não importam tanto os conteúdos ideológicos específicos, mas o fato de que simplesmente haja algo preenchendo o vácuo da consciência expropriada e desviando a atenção do segredo conhecido por todos. No contexto de seu efeito social, é talvez menos importante saber quais as doutrinas ideológicas específicas que um filme sugere aos seus espectadores do que o fato de que estes, ao voltar para casa, estão mais interessados nos nomes dos atores e em seus casos amorosos. Conceitos vulgares como "entretenimento" são muito mais adequados do que considerações pretensiosas sobre o fato de um escritor ser representante da pequena burguesia e outro, da alta burguesia (ADORNO, 1998, p. 20-21).

A citação acima ilustra a crítica de Adorno à Indústria Cultural enquanto formadora de cidadãos acríticos, conformados e submissos. Adorno diz que ao assistir um filme, o espectador é levado a se preocupar muito mais com o entretenimento, com os personagens e atores, do que com as características ideológicas transmitidas. Isso ocorreria porque o indivíduo está incluído numa sociedade que seu senso crítico não teria importância, ou pior, estaria aprisionado. $\mathrm{O}$ entretenimento seria então uma extensão da dominação - aqui de forma inconsciente - no tempo livre, nos momentos de lazer, atuando enquanto desvio do pensamento e atenção do indivíduo.

Já em Tempo Livre, Adorno aborda a relação entre o tempo livre e a indústria cultural de forma diferenciada. Ao afirmar que desde que, ao lado de Horkheimer, introduziu o conceito de indústria cultural, muito se escreveu sobre esta enquanto meio de domínio e de integração, Adorno ressalta que há um aspecto que na ocasião não conseguiram dar conta:

O crítico da ideologia que se ocupa da industrial cultural haverá de inclinar-se para a opinião de que - uma vez que os 'standards' da indústria cultural são os mesmos dos velhos passatempos e da arte menor, congelados - ela domina e controla, de fato e totalmente, a 
consciência e inconsciência daqueles aos quais se dirige e de cujo gosto ela procede desde a era liberal. Além disso, há motivos para admitir que a produção regula o consumo [...]. Deveríamos, portanto, pensar que a indústria cultural e seus consumidores são adequados um a outro. Como, porém, a indústria cultural, entretanto, tornou-se totalmente fenômeno do sempre-igual, do qual promete afastar temporariamente as pessoas, é de se duvidar se a equação entre a indústria cultural e a consciência dos consumidores é precedente (ADORNO, 1995, p. 80).

Adorno considera essa dúvida acerca da equação entre indústria cultural $e$ consciência dos consumidores a partir de um estudo feito no Instituto de Pesquisas

Sociais de Frankfurt. Esse estudo - acerca das opiniões e comportamentos da população em relação a notícias vinculadas pela mídia - teria revelado uma consciência duplicada.

Isso porque:

[...] as pessoas aceitam e consomem o que a indústria cultural lhes oferece para o tempo livre, mas com um tipo de reserva, de forma semelhante à maneira como mesmo os mais ingênuos não consideram reais os episódios oferecidos pelo teatro e pelo cinema. Talvez mais ainda: não se acredita inteiramente neles. É evidente que ainda não se alcançou inteiramente a integração da consciência e do tempo livre. Os interesses reais do indivíduo ainda são suficientemente fortes para, dentro de certos limites, resistir à apreensão [Erfassung] total. Isto coincidiria com o prognóstico social, segundo o qual, uma sociedade, cujas contradições fundamentais permanecem inalteradas, também não poderia ser totalmente integrada pela consciência. A coisa não funciona assim tão sem dificuldades, e menos no tempo livre, que, sem dúvida, envolve as pessoas, mas, segundo seu próprio conceito, não pode envolvê-las completamente sem que isso fosse demasiado para elas (ADORNO, 1995, pp. 80-81).

Visualisando essa não possibilidade de apreensão total da consciência, por parte da indústria cultural vinculada ao tempo livre, Adorno afirmou vislumbrar "uma chance de emancipação que poderia, enfim, contribuir algum dia com a sua parte para que o tempo livre [Freizeit] se transforme em liberdade Freiheir]" (ADORNO, 1995, p. 82). 


\section{Considerações finais}

O pensamento de Adorno, assim como as contribuições da chamada Escola de Frankfurt, é de importância fundamental para estudos sobre questões relacionadas ao lazer do século XX e XXI, sobretudo no que diz respeito à abordagem de assuntos que permeiam questões relacionadas à chamada Indústria Cultural. Discussões sobre suas considerações acerca da reprodução e ação de produtos da Indústria Cultural são consideradas atuais e tem sido muito abordadas nos últimos anos, como prova qualquer simples levantamento bibliográfico em busca de estudos sobre Adorno. Porém, por mais que o próprio nome do texto seja sugestivo, Tempo livre figura entre as referências bibliográficas menos citadas em estudos que abordam a questão do lazer e que tem o pensamento de Adorno como referência.

Ao estudar Tempo livre, é possível perceber considerações amplas acerca de questões relacionadas ao tempo disponível - dito livre. Isso porque, a partir desse texto é possível notar críticas de Adorno em relação à forma como, nos últimos séculos, as pessoas tem conduzido seu tempo disponível do trabalho. Nisso inclui-se a tão focada questão da Indústria Cultural, que nesse trabalho é tratada por Adorno de forma um pouco diferenciada.

Nesse texto, que figura entre os últimos trabalhos do pensador, Adorno alega encontrar, na forma de recepção estabelecida pelas pessoas em relação à Indústria Cultural, uma possibilidade de emancipação e de liberdade no tempo livre. Isso porque as pessoas não estariam totalmente acorrentadas aos seus produtos - a consciência das massas não estaria totalmente apreendida -, como chegou a afirmar anos antes. Adorno fala de interesses que impedem que a consciência dos indivíduos seja totalmente apreendida. São considerações importantes e pouco estudadas, que dizem muito sobre o pensamento de Adorno já no fim de sua vida. 
Por fim, gostaríamos de ressaltar a importância das considerações de Adorno sobre o tempo livre, na medida em que defendia um tempo verdadeiramente livre e não apenas "livre", um benefício de todos e não mero privilégio. É no tempo livre, verdadeiramente livre - que vê como ideal -, que Adorno encontra a possibilidade de liberdade. Mas para isso seria necessário pessoas aptas a defender e reconhecer seus verdadeiros interesses e vontades. Pessoas emancipadas. Enquanto a consciência das pessoas não é totalmente apreendida, Adorno vê esperança. Seu tempo livre ideal deve ser uma luta atual, para que assim possamos visualizar perspectivas de liberdade.

\section{REFERÊNCIAS}

ADORNO, T. W. Mínima Morália: reflexões a partir da vida lesada. Rio de Janeiro: Beco do Azougue, 2008.

.Palavras e Sinais. Petrópolis: Vozes, 1995.

.Prismas/ Crítica Cultural e Sociedade. São Paulo: Ática, 1998.

ASSOUN, P. L. A Escola de Frankfurt. São Paulo: Ática, 1991.

HORKHEIMER, M.; ADORNO, T. W. Dialética do Esclarecimento: fragmentos filosóficos. Rio de Janeiro: Jorge Zahar, 1985.

THOMPSON, E.P. Costumes em comum. São Paulo: Companhia das Letras, 1998.

VAZ, A. F. Reflexões de Passagem sobre o Lazer: Notas sobre a Pedagogia da Indústria Cultural. Pensar a Prática, Goiânia, v. 9, n. 1, p. 13-26, 2006. Disponível em: <http://revistas.ufg.br/index.php/fef/article/view/122/117> Acesso em: 23 jun. 2009.

\section{Endereço dos Autores:}

Renata Morais do Nascimento

Rua Manaus, 415, Glebas Califórnia.

Piracicaba - São Paulo - CEP: 13.403-141.

Endereço eletrônico: re-morais@ hotmail.com

Nelson Carvalho Marcellino

Endereço Eletrônico: marcelin@ @upernet.com.br 